\title{
Alexander Goller, Elly Heuss-Knapp Gründerin des Müttergenesungswerkes. Eine Biographie
}

Köln/ Weimar/Wien : Böhlau, 2012, 234 p., 29,90€

Marie-Claire Hoock-Demarle

\section{CpenEdition}

\section{Journals}

Édition électronique

URL : http://journals.openedition.org/ifha/8102

DOI : 10.4000/ifha.8102

ISSN : 2198-8943

Éditeur

IFRA - Institut franco-allemand (sciences historiques et sociales)

Référence électronique

Marie-Claire Hoock-Demarle, « Alexander Goller, Elly Heuss-Knapp Gründerin des Müttergenesungswerkes. Eine Biographie », Revue de l'IFHA [En ligne], Date de recension, mis en ligne le 14 avril 2015, consulté le 22 septembre 2020. URL : http://journals.openedition.org/ifha/8102 ; DOI : https://doi.org/10.4000/ifha.8102

Ce document a été généré automatiquement le 22 septembre 2020.

(CIFHA 


\title{
Alexander Goller, Elly Heuss-Knapp Gründerin des Müttergenesungswerkes. Eine Biographie
}

\author{
Köln/ Weimar/Wien : Böhlau, 2012, 234 p., 29,90€
}

Marie-Claire Hoock-Demarle

En dépit de son titre un peu réducteur, l'ouvrage se présente comme une biographie complète d'Elly Heuss, née en 1881 dans la bourgeoisie universitaire libérale de Strasbourg, où son père Friedrich Georg Knapp, dont elle est très proche, est un professeur d'économie politique reconnu. La biographie, brève - 201 pages - s'articule très classiquement selon une chronologie marquée par les grandes cassures de l'époque: Première Guerre mondiale, Troisième Reich et Après-Seconde Guerre mondiale qui sont aussi des tournants dans la vie d'Elly Knapp, épouse depuis 1908 de Theodor Heuss, futur président de la République fédérale en 1949. C'est donc d'abord une jeunesse sous l'Empire avec un premier engagement dans les organisations d'aide sociale existantes dans le lieu particulier qu'est Strasbourg à la fin du $19^{e}$ siècle. Elly Knapp est alors doublement marquée par le libéralisme social de Friedrich Naumann et l'éthique humaniste du théologien Albert Schweizer, tous deux se référant à un christianisme originel d'amour du prochain et de compassion incarné en la personne du Christ. L'engagement d'Elly Heuss-Knapp, fortement connoté par la morale chrétienne de "helfende Liebe", s'affirme pendant la guerre, puis la République de Weimar avec des publications, des conférences et des activités d'enseignement dans des écoles et institutions religieuses. La période du national-socialisme constitue une parenthèse dans la vie d'Elly Heuss : retirée de la vie publique, elle finance le ménage par des travaux de publicité à la radio et s'exprime peu sur la période sinon dans une formule assez glaçante de 1946 : «On saute (überhüpft) les douze dernières années et on commence là où on s'était arrêté » (p. 158). Dès 1945, elle revient en force sur le terrain de l'engagement public, candidate au Landtag de Bade-Wurtemberg, elle y est élue - ainsi que son mari - en 1946, donnant cette fois à son activité sociale une dimension pratique politique neuve. Devenue en 1949 femme du président, elle se consacre dès lors à sa fondation créée en 1950 le Müttergenesungswerk, (Euvre de 
convalescence des mères) organisme à l'échelle nationale offrant aux mères des centres de repos et de santé adaptés. Reposant en grande partie sur des fonds privés, cet organisme, à la croisée du social et du caritatif, se veut « une coopération pacifique entre les diverses confessions ». L'auteur, A. Goller, prend toutefois soin d'ajouter que «le Müttergenesungswerk avait toujours eu et a toujours une approche spécifiquement féminine » (p. 197). La précision, bien que tardive, est bienvenue car ce qui semble avoir été négligé ici par l'auteur c'est le rapport - ou plutôt la distance - entre la forme d'engagement et les œuvres mises en place par Elly Heuss et les positions, exigences et conquêtes faites par le mouvement des femmes en Allemagne depuis le début du siècle. Dans un ouvrage qui ne comporte pas moins de 30 pages d'une bibliographie secondaire très fournie et dont l'avant-propos décline sur plus de 20 pages la démarche scientifique choisie, avec force notes de rappel bibliographiques, très peu de place est accordée dans le texte même au mouvement des femmes ou à certaines figures féminines ayant joué un rôle majeur dans l'action sociale en faveur des femmes. Ce n'est qu'avec l'évocation d'Alice Salomon que l'auteur laisse entrevoir - toujours en note de bas de page - un antagonisme de fond qui aurait mérité d'être analysé plus avant. « Elle (E H-K) avait des difficultés avec la trop forte imbrication de l'engagement social et de la question des femmes et ce, surtout à cause de la dimension extrêmement politique » (p. 104). De même il eût été intéressant d'étudier dans le cadre des prises de position des femmes (dont le BDF) face au régime, le cas particulier d'Elly Heuss qui prend certes ses distances vis à vis du national-socialisme et se replie dans la « innere Emigration » mais salue le retour en force prôné par le régime des valeurs de la famille comme lieu de refuge et de la mère au foyer (p. 155). L'ouvrage, très instructif sur le parcours complexe des femmes allemandes dans l'engagement public, que celui-ci soit social, caritatif, voire politique, souffre de son statut d'origine de travail universitaire. Dès l'introduction, chaque terme évoqué - exemples entre autres Bildungsbürgertum ou Versicherungspolitik - déclenche un long développement très général soutenu par un lourd appareil de notes en bas de page qui tient compte scrupuleusement de toute la littérature secondaire disponible sur le sujet. 300 notes en moyenne par chapitre, fautil voir là la peur d'accusation de plagiat, la contrainte technologique de l'exhaustivité ? Des citations puisées aux textes, correspondances et archives d'Elly Heuss-Knapp, dont disposait l'auteur, auraient, dûment commentées et contextualisées, été tout aussi éclairantes. Il manque aussi à cette biographie d'une femme à la fois singulière par ses engagements et représentative de la difficile implantation des femmes allemandes dans l'action sociale publique, une notice biographique récapitulative ainsi qu'une plus large place accordée aux proches, Theodor Heuss en particulier, qui permettraient de mieux suivre la traversée par cette femme, animée par une éthique religieuse et des convictions sociales fortes, d'une période de l'histoire allemande particulièrement chaotique. 
INDEX

Index chronologique : Époque contemporaine

Thèmes : Histoire sociale, Histoire des femmes, Histoire du genre

\section{AUTEUR}

MARIE-CLAIRE HOOCK-DEMARLE

Université Paris7-Denis Diderot 